\title{
Influencia de una experiencia afectiva previa en la valoración de estímulos afectivos
}

\author{
Influence of previous affective experience in assessing affective stimuli
}

\author{
Humberto Madera-Carrillo ${ }^{1}$, Priscila Berriel-Saez², Daniel Zarabozo ${ }^{3}$, Lizbeth \\ Díaz-Díaz
}

\section{RESUMEN}

Introcuion. Se reprodujo un contexto afectivo mediante imágenes del International Affective Picture System: IAPS (valencia positiva y negativa) tomadas como experiencia previa a la valoración, con el Self-Assessment Mankin: SAM, de estímulos neutros (IAPS neutros), para determinar su influencia y la tendencia de dicha valoración a través de las exposiciones. Método. Participaron 60 varones universitarios voluntarios, de 18 a 23 ańos de edad. Se presentaron 104 ensayos con series de una y tres imágenes (52 ensayos por serie), agradables o desagradables (26 imágenes por tipo) seguidas de imágenes neutras (26), las cuales calificaron con puntuación de "1" (negativa/desagradable) a "9" (positiva/agradable). Resultados. Se encontraron diferencias después de la exposición a 3 imágenes, tanto positivas como negativas. Las imágenes neutras fueron calificadas en el mismo sentido de la carga afectiva previa. La serie de una imagen positiva no tuvo efecto. La exposición a las series negativas influyó a calificar en el mismo sentido a la imagen neutra. Se observó una disminución en la intensidad afectiva al aumentar el número de exposiciones en las series de 3 imágenes. Conclusion. La experiencia afectiva previa influye en la calificación de aquella posterior.

Unitermos. Afecto, Imágenes, Emoción, Memoria, Experiencia.

Citacion. Madera-Carrillo H, Berriel-Saez P, Zarabozo D, Diaz-Diaz L Influencia de una experiencia afectiva previa en la valoración de estímulos afectivos.

Investigación realizada en la Universidad de Guadalajara y la Universidad del Valle de Atemajac (UNIVA campus Guadalajara).

\footnotetext{
1.Doctor en Ciencia del Comportamiento por la Universidad de Guadalajara, México. Profesor Investigador del Instituto de Neurociencias, Universidad de Guadalajara, México

2.Estudiante de Posgrado en el Instituto de Neurociencias, Universidad de Guadalajara;

3.Doctor en Ciencia del Comportamiento por la Universidad de Guadalajara, México. Profesor Investigador, Jefe del Laboratorio de Psicofisiología de Procesos Perceptuales en el Instituto de Neurociencias, Universidad de Guadalajara, México.

4.Estudiante de Posgrado en el Instituto Nacional de Neurociencias.
}

\begin{abstract}
Introdution. This research implements a context affective through a set of images of the International Affective Picture System: IAPS (positive and negative valence) which were considered as affective stimuli experience previous to neutral image valuation. The objective was to determine the type of influence of previous emotional stimulation on the subsequent assessment based on the Self-Assessment Manikin: SAM, and the tendency of those assessments through exposure to multiple images. Method. 60 undergraduates participated, volunteers, with age between 18 and 23 years old. 104 trials were presented with series of one (52) and three (52) pleasant (26) or unpleasant (26) images followed by equal number of neutral images, which were qualified with a score between 1 (negative/unpleasant) to 9 (positive/ pleasant). Results. We found differences in the series of 3 images both positive and negative ratings. Neutral images were rated in the same direction of previous emotional load. The exposure to 1 image doesn't produce differences. On exposure to the series of three images was observed the tendency to reduce the emotional intensity as it increased the number of exposed images. Conclusion. The previous affective experience influences the rating of the later.
\end{abstract}

Keywords. Affect, Imagery, Expressed Emotion, Memory, Life Change Events.

Citation. Polese JC,Madera-Carrillo H, Berriel-Saez P, Zarabozo D, Diaz-Diaz L. Influence of previous affective experience in assessing affective stimuli
Dirección para correspondencia: Humberto Madera-Carrillo Instituto de Neurociencias, Universidad de Guadalajara Calle Francisco de Quevedo 180, Col. Arcos Vallarta C.P. 44130, Guadalajara, Jalisco, México Tel/Fax: (33)3818-0740 x $33371 / 33377$ E-mail: hmadera@cucba.udg.mx,maderahto@gmail.com 


\section{INTRODUCION}

Desde hace algunos años se ha tratado de aclarar el papel que juega el afecto en la vida de las personas y se ha señalado que el afecto se utiliza para referirse a las emociones y a los componentes del estado de ánimo, producto de fenómenos biológicos y sociales que lo moldean y desarrollan ${ }^{1}$.

Se ha propuesto que las emociones son preparativos para la acción y que ocurren ante estímulos significativos, produciéndose en tres sistemas reactivos: el cognitivo, el motor o conductual-expresivo, y el neurofisiológico ${ }^{2}$. Se ha sugerido que las emociones son eventos multifactoriales que se forman de una evaluación cognitiva de las situaciones, un conjunto de cambios fisiológicos, conductas visibles, un componente motivacional que se refleja en una disposición o una tendencia a la acción, y un estado subjetivo.

Un modelo reconocido en la investigación psicofisiológica para el estudio de las emociones es la teoría bifásica de las emociones ${ }^{2}$. Dicho modelo concibe la estructura de las emociones basada en dos dimensiones estratégicas: la valencia, definida como la cualidad hedónica de una experiencia afectiva, y la activación o arousal , que es la percepción de intensidad o agitación. Estas dos dimensiones han sido encontradas también en investigaciones realizadas con palabras (que representan conceptos emocionales tales como: felicidad, miedo, tristeza, etc.) y en tareas de auto-reporte y de tipo semántico, desde niños de tercer grado hasta adultos universitarios ${ }^{3}$. Las emociones están relacionadas con conductas motivadas ligadas con la supervivencia, disponiendo a las conductas desde alguno de dos sistemas motivacionales: el apetitivo -conductas de aproximación- y el defensivo o aversivo -conductas de evitación ${ }^{2,4}$.

Las emociones son procesos innatos, subjetivos, fisiológicos y conductuales importantes para la adaptación del individuo al medio ambiente. Se sabe que existe una relación entre la motivación y emoción en el sentido de que las emociones funcionan como indicadores de si la integridad del organismo está en peligro o no en relación con los eventos presentes y, por otro lado, las emociones son un tipo de motivo para acercarse o alejarse hacia determinados estímulos 5,6 .

Es obvio que los diferentes estímulos activadores de la emoción provocan tipos diferentes de respuestas emocionales. Sin embargo, todos los patrones de cambios emocionales parecen tener cierras características comunes. Se ha llamado a estas características patrón estándar de la dinámica afectiva. La Teoría del proceso oponente de la motivación ${ }^{7,8}$ plantea que los estímulos emocionales incitan a la persona a alejarse del estado de neutralidad. Este cambio induce, a su vez, un proceso oponente con una reacción emocional que contrarresta la inicial; si el proceso afectivo primario es desagradable, la reacción posterior será agradable, y viceversa, y este patrón de dinámica del afecto se verá reflejado en las conductas de los sujetos. Se considera que las reacciones emocionales tienen dos características principales: una, que son bifásicas, esto es que inicialmente una emoción tiene lugar mientras un estímulo la provoca (afecto primario) -llamado proceso primario, o proceso "a" - y una vez que ese estímulo inicia, dispara el proceso de una emoción opuesta a la primera (postrreacción afectiva) que es experimentada por el sujeto - proceso oponente, o proceso "b"-. El proceso oponente es más lento y comienza tarde con relación al proceso primario, por lo cual, cuando aquél termina, éste se manifiesta solo. La segunda; es que las reacciones emocionales tienden a cambiar en relación con la experiencia adquirida, por lo que la primera reacción emocional se va volviendo más débil cada vez mientras que la segunda reacción va adquiriendo fuerza o intensidad. Los patrones de la conducta emocional observados después de experiencias con estímulos emocionales son el resultado de la adquisición de experiencia, del proceso primario y del proceso oponente que cada vez comienza más temprano con relación al proceso primario. La Teoría del proceso oponente de la motivación asume que existen mecanismos neurofisiológicos involucrados en la conducta emocional que sirven para que el individuo mantenga una estabilidad emocional.

En el marco de la Teoría del proceso oponente de la motivación se afirma que con la exposición repetida al estímulo y, por tanto, la acumulación de experiencia, el proceso oponente va adquiriendo fuerza, por lo que eventualmente será lo suficientemente fuerte y efectivo para bloquear casi por completo la reacción emocional primaria, reforzando que el individuo recobre su estado de neutralidad emocional ${ }^{7}$. 
Por otro lado, el International Affective Picture System (IAPS) ha sido desarrollado ${ }^{4}$ como un instrumento que facilita el estudio de la experiencia afectiva, induciendo estados emocionales con estímulos controlables en el laboratorio. Existen revisiones que presentan un amplio panorama de las relaciones entre los tres aspectos de la experiencia emocional (juicio, cambios fisiológicos y conducta) y diferentes medidas cognitivas, fisiológicas y conductuales?.

El registro de la experiencia emocional estimulada por el IAPS ha sido replicado en países como: España ${ }^{10,11}$, Brasil $^{12,13}$, México ${ }^{14,15}$ y Bélgica ${ }^{16}$ y en escenarios tan diversos como el contexto carcelario ${ }^{17}$, el estudio de la regulación emocional en los trastornos mentales ${ }^{18}$ o comparado entre jóvenes y adultos ${ }^{19}$.

Por otra parte, se han realizado investigaciones enfocadas en distintos aspectos del procesamiento de las emociones en las que se utilizan estímulos pictóricos emocionales. Se ha estudiado la atención prestada a estímulos afectivos en contraste con estímulos neutros proponiéndose que, en términos generales, los estímulos emocionales provocan una atracción automática de la atención pues producen reacciones afectivas y conductas motivadas de carácter adaptativo ${ }^{20}$. Los resultados indican que los estímulos con contenido emocional -sin importar si son agradables o desagradables- producen un patrón de preferencia atencional basada en la primera fijación de la mirada, que se define como la orientación inicial de la atención visual. Lo anterior se debe a que el ser humano posee un sistema afectivo sofisticado capaz de proporcionar los mecanismos evaluativos flexibles que faciliten el mantenimiento de la estabilidad del individuo ${ }^{6}$.

Se ha observado que la exposición repetida a un estímulo nuevo basta para que las personas incrementen sus respuestas afectivas y evaluativas hacia dicho objeto ${ }^{21}$, mientras que se ha señalado que éste efecto puede verse favorecido si se tienen en cuenta variables como el tiempo y la frecuencia de la exposición, de tal forma que el incremento de la preferencia hacia un determinado estímulo previamente presentado tiende a estabilizarse tras un número elevado de repeticiones, superiores a las 30 presentaciones $^{22}$.

La presencia de un afecto puede tomar varias formas incluyendo ser el motor responsable de infinidad de reacciones $^{23}$. La conducta es influida por contingencias ambientales $^{24}$ y se ha demostrado que los estados de ánimo positivos intervienen facilitando el aprendizaje, la ejecución, el auto-control e influyen en la percepción y el contacto social ${ }^{25}$, por lo que es importante conocer si las situaciones emocionales que ha experimentado la persona provocarán un cambio en la valoración de los experiencias afectivas subsecuentes.

El objetivo del presente trabajo fue determinar la influencia que ejerce la exposición a un estímulo afectivo sobre la valoración posterior de un nuevo estímulo (de valencia neutra). Por lo cual se reprodujeron de forma experimental (con imágenes) contextos afectivos de la vida cotidiana (de corte agradable y desagradable) para observar cuál es la relación entre el estado de ánimo inducido por dichos contextos y el juicio o valoración de una situación futura. Por otra parte, también se buscó establecer si la experiencia afectiva acumulada tiene más influencia en la valoración de imágenes neutras que la experiencia afectiva única.

\section{MÉTODO}

\section{Sujetos}

Participaron 60 sujetos voluntarios de una universidad privada del occidente de México (UNIVA), con edad entre 18 y 23 años $(\mathrm{M}=20.90, \mathrm{DE}=1.46)$, hispanohablantes, sin alteraciones neuroconductuales aparentes. Ninguno había participado con anterioridad en estudios que implicasen materiales - principalmente imágenes, similares a los empleados en éste. Se excluyeron a quienes afirmaron tener antecedentes psiquiátricos familiares o haber consumido alcohol y drogas en las últimas 24 horas.

El presente trabajo fue registrado ante el Comité de Ética del Instituto de Neurociencias de la Universidad de Guadalajara y autorizado con el número: ET09 2013154.

\section{Estímulos}

Originalmente se eligieron 96 imágenes tomadas del International Affective Picture System, IAPS ${ }^{4,26,27}$, mismas que fueron divididas en tres tipos de acuerdo a la escala de dimensión de valencia del propio IAPS: a) tipo agradable: 32 imágenes con valencia entre 7.5 y 9.0 
(considerada valencia afectiva activadora positiva); b) tipo desagradable: 32 con valencia entre 1.0 y 2.5 (valencia afectiva activadora negativa), y c) tipo neutro: 32 con valencia afectiva neutra entre 4.0 y 6.0 (sólo objetos inanimados). Posteriormente se realizó un pilotaje sobre los puntajes de las imágenes neutras en el cual se les pidió a 30 sujetos voluntarios, estudiantes universitarios con edad entre 18 a 24 años que valoraran las 32 imágenes de tipo neutro. Se encontró que el promedio de 4 de las imágenes era mayor a 6 mientras que 2 imágenes tenía un promedio menor a 4, debido a esto, se acordó eliminar estas 6 imágenes dejando las 26 imágenes de tipo neutro con valencia entre 4.23 y 5.70 ( $\mathrm{Md} 4.99$, DE 0.45). También fueron eliminadas las 6 imágenes tipo agradable con valencia menor, así como las 6 imágenes tipo desagradable con valencia mayor.

Los 26 estímulos de valencia positiva (Md 7.78, DE 0.16), fueron los identificados en el IAPS como: $1460,5210,4150,1920,2040,1750,5825,8510,2154$, $2260,1440,2080,1710,5833,2050,4680,5700,8170$, 2030, 8370, 8420, 2070, 2340, 1441, 5760, 8190.

Los 26 estímulos de valencia negativa (Md 2.23, DE 0.17), tienen numeración en el IAPS como: 9414, 9520, 9413, 2205, 6570, 3191, 9325,9910, 2095, 3301, 9254, 9560, 9075, 3230, 3005.1, 2703, 9185, 3350, 2800, 9410, 9340, 3180, 9040, 9433, 9183, 9220.
Los estímulos neutros seleccionados fueron: 6150 , 7000, 7002, 7004, 7009, 7010, 7020, 7030, 7034, 7035, 7050, 7080, 7150, 7170, 7175, 7179, 7205, 7207, 7211, 7217, 7233, 7491, 7705, 7950, 7012 y 7017.

Por otra parte, para controlar la percepción de intensidad o agitación de cada imagen se consideró la dimensión de activación (arousal) de tal forma que todas las imágenes seleccionadas tuvieron un puntaje menor a 6.5 en esta dimensión.

Las imágenes neutras se utilizaron como estímulos prueba, a las cuales los sujetos participantes asignaron un valor numérico del 1 al 9. Las imágenes activadoras tanto positivas como negativas precedieron a las imágenes neutras en cada ensayo.

\section{Diseño de ensayo con una imagen de estímulo}

Una vez definidos los estímulos, se definió el orden de aparición de las imágenes neutras, positivas y negativas de forma aleatoria. A continuación con el orden obtenido en cada tipo de imagen se formaron pares de imágenes positiva-neutra y negativa-neutra. Luego se tomó el conjunto de pares de imágenes negativa-neutra y se organizó el orden de aparición de dichos pares de manera aleatoria.

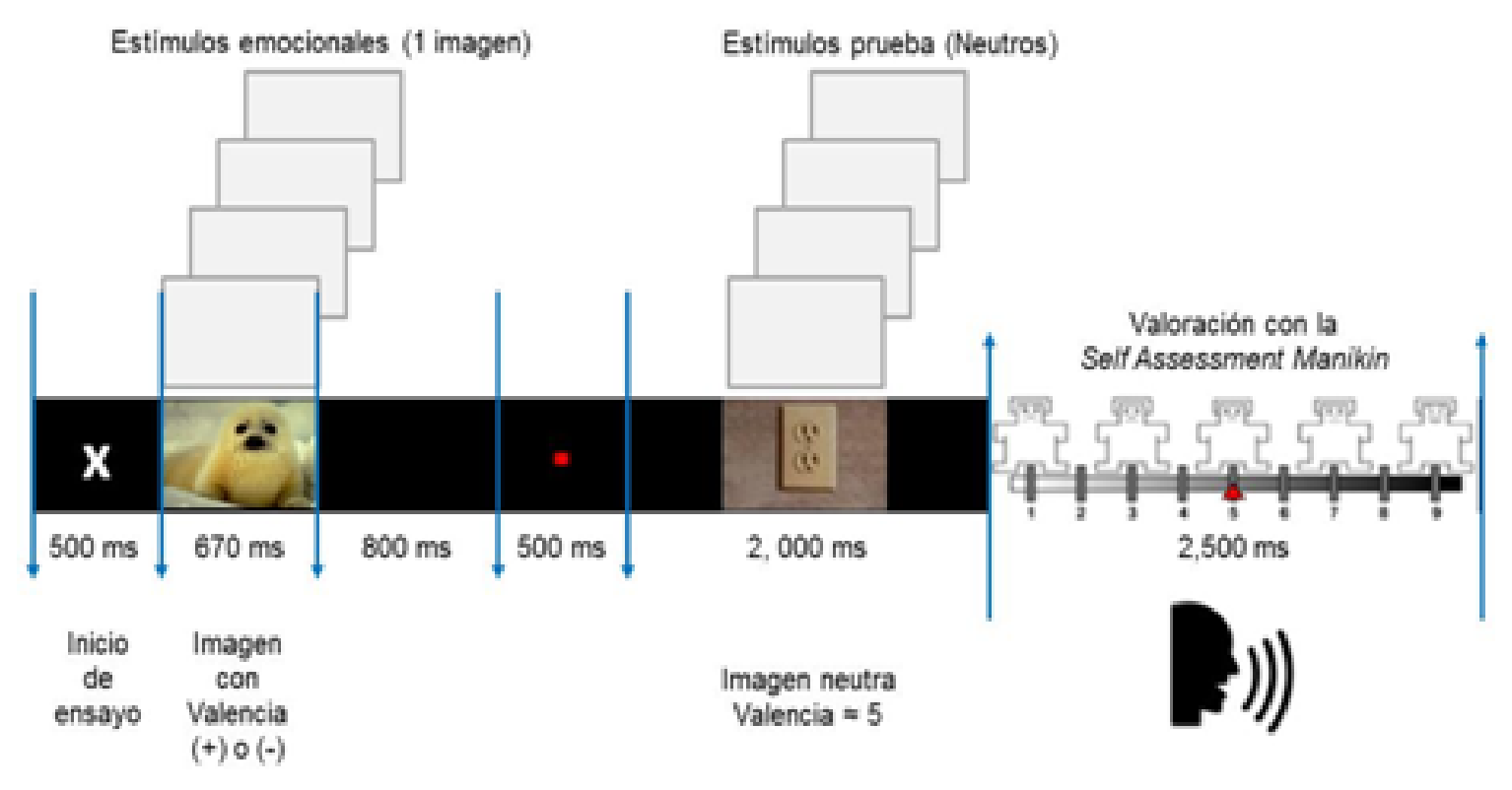

Figura 1. Esquema del ensayo con una imagen previa a la valoración de una imagen neutra. Los bloques de estímulos positivos y negativos se presentaron en forma separada. Esta figura ha sido diseñada por los autores. 
Con estos pares se elaboraron 52 ensayos, 26 de pares de imágenes positiva- neutra (bloque positivo), y 26 de imágenes negativa-neutra (bloque negativo). Cada bloque se presentó por separado.

El diseño de cada ensayo fue el siguiente: 1. presentación de una cruz de atención al centro de la pantalla $(500 \mathrm{~ms})^{28} ; 2$. imagen con valencia (llamada imagen emocional) del bloque en curso $(670 \mathrm{~ms}) ; 3$. intervalo en negro (800ms), 4. punto rojo en fondo negro (punto de fijación) (500ms), 5. la imagen neutra (2s), y finalmente, 6. la escala Self-Assessment Manikin (SAM) (2.5s), durante este último periodo el participante emitió en voz alta la puntuación de la imagen neutra, que fue registrada manualmente por el investigador. El esquema de este tipo de ensayo puede observarse en la Figura 1 (Ejemplo para el bloque positivo).

\section{Diseño de ensayo con tres imágenes de estímulo}

En seguida, se realizó una nueva selección aleatoria, esta vez para agregar dos imágenes más a cada uno de los pares ya establecidos anteriormente, formando triadas de imágenes con valencia positiva o negativa ligadas a su respectiva imagen neutra. El orden de los conjuntos se estableció de forma aleatoria.

Con estas combinaciones se hicieron 52 nuevos ensayos, 26 ensayos de tres imágenes previas con valencia positiva (bloque positivo), y 26 con tres imágenes de valencia negativa (bloque negativo). el esquema de aquellos descritos anteriormente con una imagen en donde cada una de las tres imágenes con valencia (imágenes emocionales) (670 ms) se presentaron separadas por un intervalo en negro $(100 \mathrm{~ms})$. El esquema aparece en la Figura 2.

\section{Procedimiento}

Se elaboraron 4 bloques de 26 ensayos cada uno tomando como referencia la cantidad de imágenes previas a la neutra y la valencia de éstas: $1+$ (una imagen con valencia positiva), 3+ (tres imágenes positivas), 1- (una imagen negativa), 3- (tres imágenes negativas). Cada secuencia fue asignada en orden de aparición a cada uno de 60 participantes (15 por secuencia).

A cada voluntario se le explicó detalladamente el procedimiento y las implicaciones de su participación en la investigación y se le pidió que firmara una carta de consentimiento informado. A continuación, se le invitó a sentarse cómodamente frente a una computadora portátil con una pantalla de 14 pulgadas a una distancia de 50 $\mathrm{cm}$ (aprox). Este estudio fue aprobado por el Comité de Ética del Instituto de Neurociencias de la Universidad de Guadalajara, con el número de registro ET 092013-154.

\section{Análisis estadístico}

El análisis estadístico fue llevado acabo utilizando la versión 20 del software SPSS (Statistic Package for the Social Science) ${ }^{29}$.

Los ensayos con tres imágenes previas siguieron

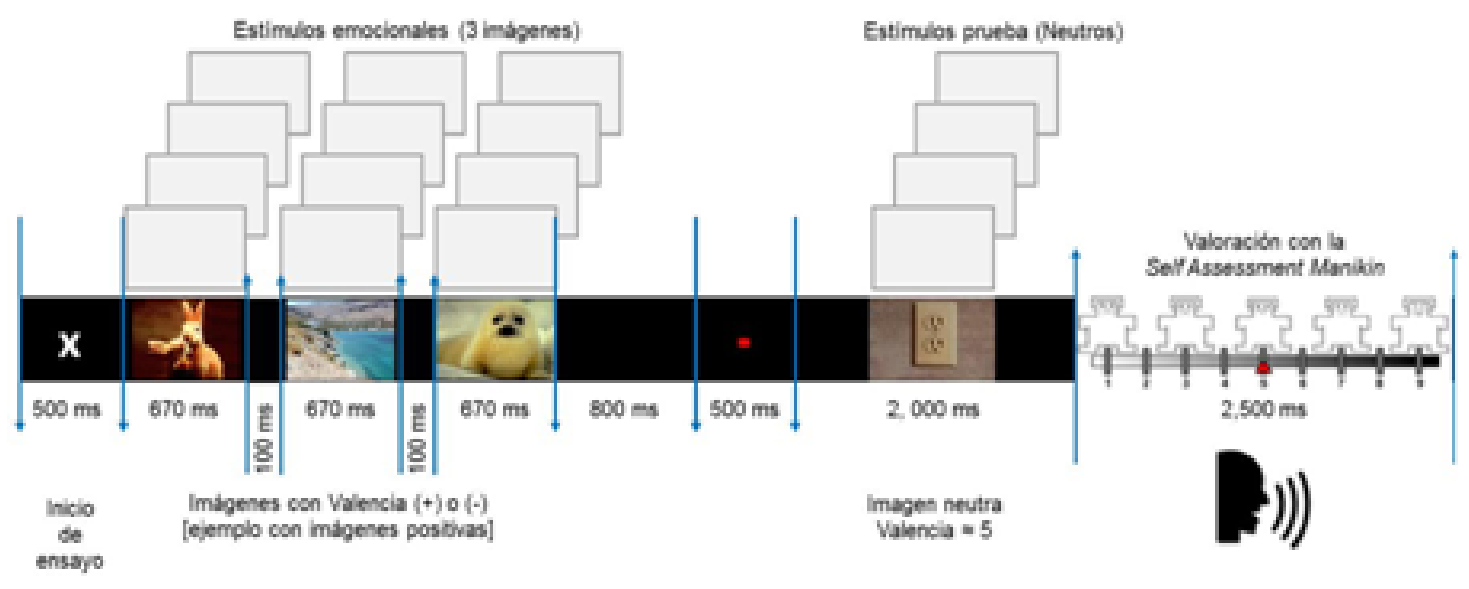

Figura 2. Esquema del ensayo con tres imágenes previas a la valoración de una imagen neutra. Los bloques de estímulos positivos y negativos se presentaron en forma separada. Esta figura ha sido diseñada por los autores. 
Análisis previo:

Se evaluó la diferencia de los promedios de cada aplicación (1+, 1-, 3+, 3-) contra los valores obtenidos en la valoración original de las imágenes neutras (rango final de valencia entre 4.23 y 5.70 [Md 4.99, DE 0.45]) con sendas pruebas t para grupos independientes.

\section{Análisis 1}

Para evaluar la calificación que los participantes asignaron a las imágenes neutras después de ver diferente cantidad de imágenes ( 1 o 3 ) con diferente valencia (positiva o negativa) se aplicó un análisis de varianza univariante de dos factores con un diseño de 2 x 2, correspondiente a Valencia (positiva [+], negativa [-]) x Cantidad (una imagen, tres imágenes).

\section{Análisis 2}

Para observar la experiencia adquirida por los participantes (la familiaridad con la valencia de las imágenes previas), se dividieron en tercios las valoraciones de cada secuencia. Primer tercio: calificaciones promedio otorgadas a los primeros ocho ensayos; Segundo tercio: calificaciones promedio del décimo al decimoséptimo ensayo; y Tercer tercio: calificaciones promedio del decimonoveno hasta el vigésimo sexto ensayo.

Se realizó un análisis de varianza de un factor de medidas repetidas (1er tercio, 2 do tercio, 3er tercio), por separado para las valoraciones precedidas por imágenes positivas y aquellas precedidas por imágenes negativas.

\section{RESULTADOS}

\section{Análisis previo}

Los promedios y desviaciones estándar del grupo de 26 imágenes neutras calificadas después de que los sujetos fueron expuestos a imágenes emocionales son los siguientes: después de la exposición a una imagen positiva [1+] $\mathrm{M}=4.48$ (DE 0.57), una imagen negativa [1-] $\mathrm{M=}$ 4.36 (DE 0.52), tres imágenes positivas [3+] $\mathrm{M}=5.89$ (DE 0.51) y tres imágenes negativas [3-] $\mathrm{M}=4.47$ (DE 0.31 ), las cuales fueron comparadas con los promedios del grupo de imágenes neutras de referencia ( $\mathrm{Md} 4.99$, DE 0.45, ver el apartado de "Estímulos").
Todas las comparaciones de estos grupos de imágenes contra los valores del grupo de imágenes neutras de referencia por medio de la prueba de t de Student para muestras correlacionadas presentaron las siguientes diferencias: $[1+] \mathrm{t}(25)=4.57, \mathrm{p}<0.001)$. Las demás comparaciones también reportaron diferencias: [1-] $\mathrm{t}(25)=4.91$, $\mathrm{p}<0.001 ;[3+] \mathrm{t}(25)=-8.13, \mathrm{p}<0.001 ;[3-] \mathrm{t}(25), \mathrm{p}<0.001$.

\section{Análisis 1}

Aunque el ANOVA reportó diferencia en los factores Valencia $(\mathrm{F}(1,56)=6.054 \mathrm{p}<0.02)$ y Cantidad de imágenes $(\mathrm{F}(1,56)=5.855, \mathrm{p}<0.02)$ la interacción fue sig-

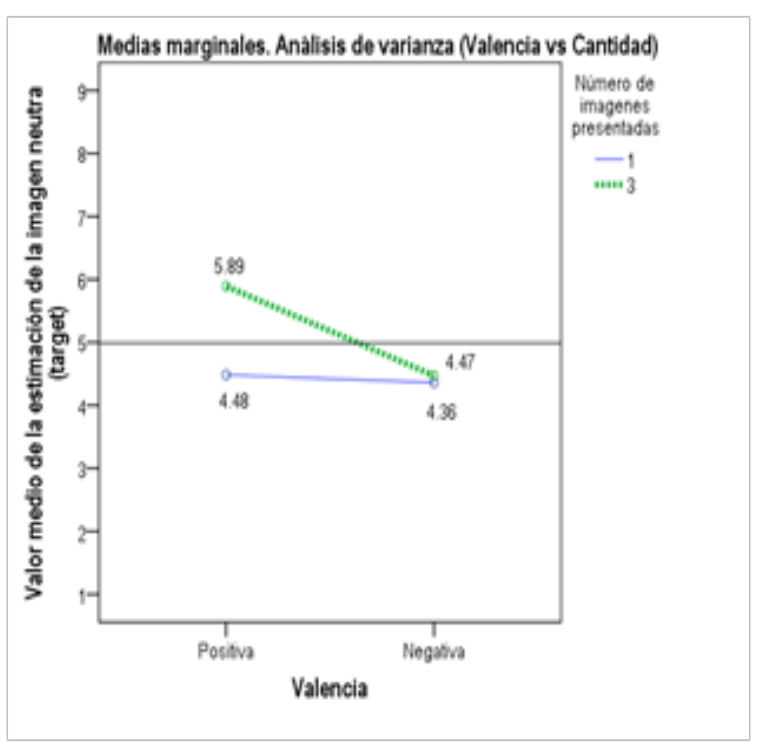

Figura 3. Medias marginales del análisis de varianza de dos factores (Valencia vs Cantidad). La línea de referencia corresponde al promedio de la valencia de las imágenes neutras (valoración original: 4.99).

Tabla 1

Promedio y desviación estándar de las valoraciones en cada bloque.

\begin{tabular}{lcccc}
\hline N=30 x grupo & Media & DE & F & $\boldsymbol{p}$ \\
\hline Valencia Negativa & 4.41 & 1.05 & 6.054 & 0.017 \\
Valencia Positiva & 5.18 & 1.50 & & \\
& & & & \\
1 imagen previa & 4.42 & 1.32 & 5.855 & 0.019 \\
3 imágenes previas & 5.18 & 1.27 & & \\
& & & & \\
\hline Interacción & & & 4.227 & 0.043 \\
Valencia*Cantidad & & & & \\
\hline
\end{tabular}


nificativa $(\mathrm{F}(1,56)=4.277, \mathrm{p}<0.005)$, en donde el promedio marginal de la exposición a 3 imágenes positivas es el que marca la diferencia (Figura 3, Tabla 1).

\section{Análisis 2}

Los resultados del análisis de varianza de medidas repetidas (1er tercio, 2 do tercio, 3er tercio), sobre los factores "tres imágenes positivas" $(\mathrm{F}(2,28)=0.788, \mathrm{p}>0.05)$ y "tres imágenes negativas" $(\mathrm{F}(2,28)=0.450, \mathrm{p}>0.05)$ no mostraron diferencias significativas, pese a la tendencia observada de confluir en dirección del valor de las imágenes neutras de referencia (Figura 4).

\section{DISCUSIÓN}

Nuestros resultados indican que la presentación previa de imágenes emocionales influye en la valoración posterior de imágenes neutras, lo cual apoya la afirmación de estudios previos ${ }^{21}$ en el sentido del incremento de la respuesta afectiva y evaluativa. También en estudios previos se ha observado que la exposición repetida a un estímulo nuevo basta para que las personas incrementen sus respuestas afectivas y evaluativas hacia dicho objeto, y que se señala que éste efecto puede verse favorecido si se tienen en cuenta variables como el tiempo y la frecuencia de la exposición, de tal forma que el incremento de la preferencia hacia un determinado estímulo previamente presentado tiende a estabilizarse tras un número elevado de repeticiones, superiores a las 30 presentaciones $^{22}$. No obstante, en este estudio se observaron diferencias al calificar imágenes neutras precedidas de una sola imagen afectiva, lo cual indica que las imágenes afectivas pueden incrementar la respuesta afectiva posterior con sólo una exposición.

Los resultados del primer análisis apoyan los resultados descritos antes sobre la exposición repetida para las imágenes que incrementa la respuesta afectiva en la valoración de la imagen neutra posterior en el mismo sentido de la valencia de las imágenes emotivas presentadas, por ello, la explicación a los resultados en el análisis 1 son: a) las imágenes positivas presentadas en cantidades de 3 en un solo ensayo, tienen un afecto de acumulación y originan que la valoración de la imagen neutra posterior a ellas sea definida positivamente; b) la presentación de una sola imagen positiva en cada ensayo no tiene valor acumulativo, por el contrario, permite la comparación con la

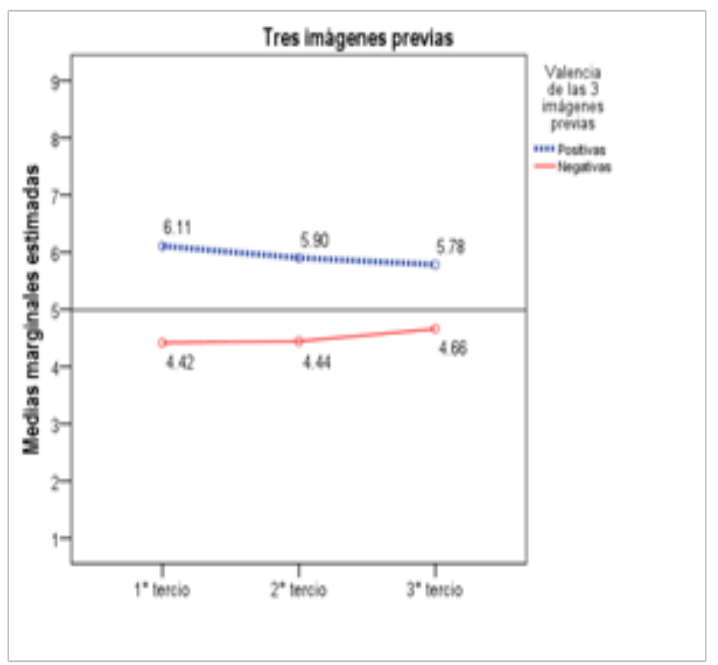

Figura 4. Medias marginales de los análisis de varianza unifactorial (1er tercio, 2do tercio, 3er tercio) realizados por separado para las valoraciones de las imágenes neutras posteriores a la presentación de 3 imágenes con valencia positiva y negativa.

imagen neutra y resalta el carácter menos positivo de la imagen neutra lo que polariza su valoración asimilándola como negativa; c) por otro lado, las imágenes negativas causan un efecto de saturación desde la presentación de la primera imagen, por lo que tanto en imágenes unitarias o en grupos de tres la valoración negativa es participada a la imagen neutra.

Definitivamente, es imposible asumir que la valencia per se es la que influye en el juicio emocional sin incluir los valores de activación, no obstante este aspecto no pudo ser evaluado en este estudio ya que se mantuvo la activación controlada entre 5 y 6.5 , pero no descartamos que con valores superiores el efecto de impresión sea mayor tanto con una como con tres imágenes.

La observación de un efecto de disminución de la calificación emocional y que las calificaciones dadas a los primeros tercios fueron más extremas que las de los terceros concuerda con lo descrito en la Teoría del proceso oponente ${ }^{7,8}$, no obstante el número de presentaciones del estímulo fue pequeño y consideramos que eso evitó que los valores disminuyeran lo suficiente al final de la exposición para establecer diferencias, además, la exposición a una imagen neutra para valorar la impresión de las imágenes emocionales puede interferir con el proceso oponente iniciado en las segundas. Posiblemente este diseño no sea el mejor modelo para evaluar el proceso oponente. 


\section{CONCLUSIONES}

Las imágenes emotivas con una activación controlada provocan una marca emocional que perdura hasta la siguiente presentación secuencial de una imagen. La impresión causada por las imágenes emocionales repetidas tiende a imprimir en la valoración posterior el mismo sentido que la valencia de dichas imágenes previas.

\section{REFERENCIAS}

1.Eich E, Kihlstrom H, Bower G, Forgas J, Niedenthal P. Cognición y emoción. España: Editorial Desclée de Brouwer; 2003.

2.Lang PJ. The emotion probe. Studies of motivation and attention. Am Psychol 1995;50:372-85. http://dx.doi.org/10.1037/0003-066X.50.5.372

3.Russell JA, Ridgeway D. Dimensions underlying children's emotions concepts. Dev Psychol 1983;19:795-804. http://dx.doi.org/10.1037/0012$\underline{1649.19 .6 .795}$

4.Lang PJ, Bradley MM, Cuthbert BN. International affective picture system (IAPS): Technical manual and affective ratings. Gainesville, Florida: NIMH Center for the Study of Emotion and Attention (CSEA); 1997, 5p.

5.Ballesteros $S$. ¿Existen procesos afectivos no concientes? Evidencia a partir del efecto de la mera exposición y del priming afectivo. Psicothema 1998;10:55170.

6.Reeve J. Motivación y Emoción. 3a ed. México: McGraw-Hill Interamericana; 2003.

7.Solomon RL, Corbit JD. An opponent-process theory of motivation. I. Temporal dynamics of affect. Psychol Rev 1974;81:119-45.

8.Domjan M. Principios de aprendizaje y conducta. 6 ed: Cengage Learning; 2011.

9.Bradley MM, Lang PJ. The International Affective Picture System (IAPS) in the study of emotion and attention. In: Coan JA, Allen JJB, editors. Handbook of emotion elicitation an assessement. Oxford: University Press; 2007. p. 29-46.

10.Moltó J, Montañés S, Poy R, Segarra P, Pastor MC, Tormo MP, et al. Un nuevo método para el estudio experimental de las emociones: el "International Affective Picture System” (IAPS). Adaptación española. Rev Psicol Gen Apl 1999;52:55-87.

11.Vila J, Sánchez M, Ramírez I, Fernández M, Cobos P, Rodríguez $\mathrm{S}$, et al. El sistema internacional de imágenes afectivas (IAPS): Adaptación española. Segunda Parte. Rev Psicol Gen Apl 2001;54:635-57.

12.Lasaitis C, Riveiro RL, Amodeo OF. Brazilian norms for the International Affective Picture System (IAPS) -comparison of the affective ratings for new stimuli between brazilian and Nort-American subjects. J Bras Psiquiatr 2008;57:270-5. http://dx.doi.org/10.1590/S0101-81082004000200008
13.Ribeiro RL, Pompeia S, Bueno OF. Comparison of Brazilian and American norms for the International Affective Picture System (IAPS). Rev Bras Psiquiatr 2005;27:208-15. http://dx.doi.org/10.1590/S1516-44462005000300009 14.Chayo-Dichy R, Velez AE, Arias N, Castillo-Parra G, Ostrosky-Solis F. Valencia, Activación, dominancia y contenido moral, ante estímulos visuales con contenido emocional y moral: un studio en población mexicana. Rev Espan Neuropsicol 2003;5:213-25.

15.Madera-Carrillo H, Zarabozo D, Ruíz-Díaz M, Berriel-Saez P, Evangelista-Plascencia EJ, Sámano M. Imágenes emocionales en población mexicana: caracterización el IAPS. Rev Mex Psicol 2011;Número especial memoria in extenso:1439-40.

16.Verschuere B, Crombez G, Koster E. The International Affective Picture System: a flemish validation study. Psychol Belg 2001;41:205-17.

17.Pastor MC. Modulación del reflejo de sobresalto y medidas autonómicas en psicópatas encarcelados (Thesis). Castellón: Universitat Jaume i de Castelló; 1999.

18.Jarayo C, de la Vega I, Díaz-Marsá M, Montes A, Carrazco JL. Aplicaciones del International Affective Picture System en el estudio de la regulación emocional de los trastornos mental. Act Espan Psiquiatr 2008;36:177-82.

19.Backs RW, da Silva SP, Han K. A comparison of younger and older adults' Self-Assessment Manikin ratings of affective pictures. Exp Aging Res 2005;31:421-40. http://dx.doi.org/10.1080/03610730500206808

20.Gutiérrez M, Gutiérrez A, Avero P. Patrones de atención visual a estímulos emocionales pictóricos. Rev Electr Mot Emoc 2007;6: Available from: http:// reme.uji.es/articulos/avil/lj3022501105/texto.html.

21.Zajonc RB. Attitudinal effects of mere exposure. J Pers Soc Psychol 1968;9(2, part 2):1-28. http://dx.doi.org/10.1037/h0025848

22.Bornstein RF. Exposure and affect: overview and meta-analysis research, 1968-1987. Psychol Bull 1989;106:265-88. http://dx.doi.org/10.1037/00332909.106.2.265

23.Núńez J. Aprendizaje incosciente. Condicionamiento a estímulos visuales subliminales. Madrid: Universidad Pontificia Comillas Madrid; 1998.

24.Plazas E. BF Skinner: la búsqueda de orden en la conducta voluntaria. Univ Psychol 2006;5:371-84.

25.Paez D, Carbonero A. Afectividad, cognición y conducta social. Psicothema 1993; 5:133-50.

26.Lang PJ, Bradley MM, Cuthbert BN. International affective picture system (IAPS): Affective ratings of picture and instruction manual. Gainesville: University of Florida; 2008.

27.Lang PJ, Bradley MM, Cuthbert BN. International affective picture system (IAPS): Instruction manual and affective ratings. Gainesville: The Center for Research in Psychophysiology, University of Florida; 2005.

28.Avero P, Calvo MG. Affective Priming with Pictures of Emotional Scenes: The Role of Perceptual Similarity and Category Relatedness. Span J Psychol 2006;9:10-8. http://dx.doi.org/10.1017/S1138741600005928

29.SPSS Inc. IBM SPSS Statisctics. Statistical Package for the Social Sciences. 20 ed. Chicago. EEUU, IBM Corporation; 2010. 